\title{
GABA regulates synaptic integration of newly generated neurons in the adult brain
}

\author{
Shaoyu Ge ${ }^{*}$, Eyleen L.K. Goh ${ }^{*}$, Kurt A. Sailor, Yasuji Kitabatake, Guo-li Ming, and Hongjun \\ Song \\ Institute for Cell Engineering, Departments of Neurology and Neuroscience, Johns Hopkins \\ University School of Medicine, Baltimore, MD 21205, USA
}

\section{Abstract}

Adult neurogenesis, the birth and integration of new neurons from adult neural stem cells, represents a striking form of structural plasticity and regenerative capacity of the adult mammalian brain, including humans ${ }^{1-8}$. Accumulating evidence suggests that neuronal activity regulates adult neurogenesis and new neurons contribute to specific brain functions ${ }^{1-8}$. The mechanism that regulates the integration of newly generated neurons into the pre-existing functional circuitry in the adult brain is unknown. Here we show that newborn granule cells in the dentate gyrus of the adult hippocampus are tonically activated by ambient $\gamma$-aminobutyric acid (GABA) before they are sequentially innervated by GABAergic and glutamatergic synaptic inputs. GABA, the major inhibitory neurotransmitter in the adult brain, initially exerts an excitatory action on newborn neurons due to their high cytoplasmic chloride content ${ }^{9-12}$. Conversion of GABA-induced depolarisation/ excitation into hyperpolarisation/inhibition in newborn neurons leads to significant defects in their synapse formation and dendritic development in vivo. Our study reveals an essential role of GABA in the synaptic integration of newly generated neurons in the adult brain and suggests an unexpected mechanism for activity-dependent regulation of adult neurogenesis where newborn neurons may sense neuronal network activity through tonic and phasic GABA activation.

Using a retroviral strategy to express green fluorescent protein (GFP) specifically in proliferating cells and their progeny 6,7 , we examined the synaptic integration of newly generated granule cells (DGCs) in the dentate gyrus of adult mice (Fig. 1). Retroviral labelling provides adequate time resolution for birth dating and does not appear to affect the neuronal development of the labelled cells (Fig. 1a; Supplementary Fig. 1; supplementary videos 1, 2 and supplementary Table 1). To monitor the integration process of new neurons in the adult brain, we recorded from $\mathrm{GFP}^{+}$DGCs in slices acutely prepared from virus-infected animals by whole-cell patch-clamp (See methods). At 3 days post viral injection ( $3 \mathrm{dpi}$ ), none of the $\mathrm{GFP}^{+}$cells recorded under voltage-clamp $\left(\mathrm{V}_{\mathrm{m}}=-65 \mathrm{mV}\right)$ exhibited any spontaneous synaptic currents (SSCs), or any detectable evoked postsynaptic currents (PSCs) when the perforant pathway was stimulated ( $n=15 ;$ Fig. 1b-d). Interestingly, bath application of bicuculline (100 $\mu \mathrm{M})$, a specific $\mathrm{GABA}_{\mathrm{A}} \mathrm{R}$ antagonist ${ }^{13,14}$, revealed the presence of a tonic current in all

Correspondence should be addressed to: Hongjun Song Institute for Cell Engineering, Departments of Neurology and Neuroscience, Johns Hopkins University School of Medicine, 733 N. Broadway, BRB735, Baltimore, MD 21205, USA; Tel: 443-287-7499; Fax: 410-614-9568; E-mail:shongju1 @bs.jhmi.edu.

these authors contribute equally to this work.

Author Contributions S-y. G did virus injection and electrophysiology, E.G. engineered retroviral constructs and did characterization, K.S. did immunohistochemistry and confocal imaging analysis, Y.K. helped with molecular biology, G-1. M. and H.S. are both senior authors and are responsible for project planning. All authors discussed the results and commented on the manuscript.

Author Information Reprints and permissions information is available at npg.nature.com/reprintsandpermissions. The authors declare no competing financial interests.

Correspondence and requests for materials should be addressed to H.S. (shongju1@bs.jhmi.edu.) or G-1. M. (gming1@bs.jhmi.edu.).

Supplementary Information is linked to the online version of the paper at www.nature.com/nature. 
$\mathrm{GFP}^{+}$DGCs recorded from 3 dpi and onwards ( $n=48$; Fig. 1b). SR95531 (100 $\left.\mu \mathrm{M}\right)$, another $\mathrm{GABA}_{\mathrm{A}} \mathrm{R}$ antagonist ${ }^{13,14}$, also abolished the tonic current (Supplementary Fig. 2a). On the other hand, NO-711 (2.5 $\mu \mathrm{M})$, a specific GABA transporter inhibitor ${ }^{13,14}$, significantly enhanced the tonic current (Supplementary Fig. 2b). Interestingly, stimulation of local interneurons, such as basket cells ${ }^{15}$, also enhanced the tonic currents in newborn DGCs (Supplementary Fig. 2c). Thus, newborn DGCs in the adult brain are tonically activated by ambient GABA before any detectable phasic/synaptic activation. Bicuculline $(10 \mu \mathrm{M})$ sensitive GABAergic PSCs (Fig. 1c) and CNQX (50 $\mu \mathrm{M})$-sensitive glutamatergic PSCs (Fig. 1d) were first detected in some $\mathrm{GFP}^{+}$DGCs at 7 dpi and 14 dpi, respectively. These results demonstrate that newborn neurons in the adult brain, as in neonates, follow a stereotypical integration process-receiving tonic GABA activation first, followed by GABAergic synaptic inputs and finally glutamatergic synaptic inputs $9,10,16-20$.

To determine the nature of GABA activation, we made perforated whole-cell patch-clamp recordings with gramicidin $(25 \mu \mathrm{g} / \mathrm{ml})$ to allow reliable recording of GABA-induced currents $^{21}$. We found that the reversal potential for GABA-induced currents $\left(\mathrm{E}_{\mathrm{GABA}}\right)$ in GFP + DGCs gradually decreased during maturation (Fig. 2a; Supplementary Fig. 3a), indicating a higher concentration of intracellular chloride $\left(\left[\mathrm{Cl}^{-}\right]_{\mathrm{i}}\right)$ in younger neurons (Supplementary Fig. $4)$. The resting membrane potential $\left(\mathrm{V}_{\text {rest }}\right)$, however, only decreased slightly over time (Fig. 2a; Supplementary Fig. 3b). Interestingly, $V_{\text {rest }}$ was significantly more negative than $\mathrm{E}_{\mathrm{GABA}}$ during the first two weeks (Fig. 2a). Thus, GABA initially depolarises newborn DGCs in the adult brain. The polarity of GABA action is largely determined by the neuronal $\left[\mathrm{Cl}^{-}\right]_{\mathrm{i}} 9-12$. Sequential expression of the $\mathrm{Na}^{+}-\mathrm{K}^{+}-2 \mathrm{Cl}^{-}$transporter $\mathrm{NKCC} 1\left(\mathrm{a} \mathrm{Cl}^{-}\right.$importer) and the $\mathrm{K}^{+}$coupled $\mathrm{Cl}^{-}$transporter $\mathrm{KCC} 2$ (a Cl${ }^{-}$exporter) is believed to underlie the conversion from depolarisation to hyperpolarisation by GABA during neuronal maturation in the fetal brain ${ }^{9-}$ 12. We found that newborn DGCs $\left(\mathrm{DCX}^{+}\right)$in the adult brain express high levels of NKCC1 and little KCC2 (Fig. 2b and supplementary Fig. 5b,c). We constructed several retroviruses expressing specific short hairpin RNAs (shRNA) against different regions of mouse $\mathrm{NKCC}^{2} 2$. We found that two different NKCC1-shRNAs, but not the control shRNA, almost completely knocked down the expression of NKCC1 as shown by Western blot analysis (Supplementary Fig. 5a) and in newborn DGCs in vivo by immunostaining (Fig. 2b and Supplementary Fig. 5b). None of these shRNAs affected KCC2 expression in the infected cells in vivo (Fig. 2b; Supplementary Fig. 5c). GFP ${ }^{+}$DGCs expressing shRNA-NKCC1, but not the control shRNA, exhibited significantly lower $\left[\mathrm{Cl}^{-}\right]_{\mathrm{i}}$ (Supplementary Fig. 4). In addition, $\mathrm{E}_{\mathrm{GABA}}$ was more negative than $\mathrm{V}_{\text {rest }}$ in the shRNA-NKCC1${ }^{+}$DGCs throughout their development (Fig. 2c). Under gramicidin perforated patch recording, tonic GABA activation led to hyperpolarisation of these shRNA-NKCC $1^{+}$DGCs at $7 \mathrm{dpi}$, in contrast to depolarisation of the control newborn DGCs (Fig. 2d). The amplitude of the tonic GABA currents under whole-cell recording, however, was similar (Fig. 2d), suggesting that the expression levels of functional $\mathrm{GABA}_{\mathrm{A}} \mathrm{Rs}$ that are responsible for the tonic activation was not significantly affected.

We next examined the synaptic integration of new DGCs in the absence of GABA-induced depolarisation in vivo. GABAergic synaptic transmission was examined in the presence of kynurenic acid (Kyn, $5 \mathrm{mM}$ ) to block ionotropic glutamatergic currents (Fig. 3a-c). We could not detect any PSCs in shRNA-NKCC1 ${ }^{+}$DGCs at 7 dpi (Fig. 3a,b). The mean amplitude of the recorded PSCs at 14 and 28 dpi was only about $12 \%$ and $65 \%$ of those observed in control $\mathrm{GFP}^{+}$DGCs, respectively (Fig. 3b). In addition, the frequency of SSCs recorded at 28 dpi, but not the mean amplitude, was also significantly reduced (Fig. 3c), further indicating defects in the GABAergic synaptogenesis of shRNA-NKCC $1^{+}$cells. We then examined glutamatergic synaptic transmission in the presence of bicuculline $(10 \mu \mathrm{M})$ to block ionotropic GABAergic currents (Fig. 3d-f). We could not detect any PSCs or SSCs in shRNA-NKCC1 ${ }^{+}$DGCs at 14 dpi and the percentage of cells recorded with PSCs was greatly reduced at 28 dpi (Fig. 3d,e). 
Moreover, the mean peak amplitude of PSCs and frequency of SSCs at 28 dpi were only about $42 \%$ and $7 \%$ of those from control GFP ${ }^{+}$DGCs (Fig. 3e,f), respectively. The mean amplitude of SSCs, however, was not significantly different (Fig. 3f), suggesting that there were no general defects in the expression of receptors at the synapses. We also examined the synaptic integration of newborn DGCs in NKCC1 germ-line knockout mice ${ }^{23}$. Despite the caveats of defects and potential compensation during embryonic development ${ }^{11}$, we found similar defects in the formation of GABAergic and glutamatergic synapses by newborn DGCs in the adult NKCC1-/- mice (Supplementary Fig. 6). Taken together, these results suggest that GABA-induced depolarisation is essential for the establishment of functional GABAergic and glutamatergic synapses for newly generated DGCs in the adult brain.

To directly examine the functional role of GABA-induced depolarisation in the structural plasticity of newborn neurons, we used confocal microscopy to reconstruct the dendritic arborisation of $\mathrm{GFP}^{+}$DGCs at $14 \mathrm{dpi}$ (Fig. 4a), when active synaptogenesis occurs for GABAergic and glutamatergic inputs. Consistent with results from the electrophysiological studies, we found that shRNA-NKCC $1^{+}$DGCs exhibited significant defects in their dendritic arborisation (Fig. 4b, c). The total dendritic length and branch number of these new neurons, as well as their dendritic complexity, were significantly reduced. In addition, we found that injection of $\mathrm{GABA}_{\mathrm{A}} \mathrm{R}$ agonist (pentobarbital) 20 appears to promote dendrite growth of newborn DGCs in vivo (Supplementary Fig. 7). Thus, GABA-induced depolarisation/ excitation regulates the dendritic development of newborn neurons in the adult brain.

Combining electrophysiology with retrovirus-mediated birth-dating and labelling, we delineated the sequential steps of the integration of newly generated neurons into the preexisting functional circuitry in the adult brain: from tonic GABA activation to GABAergic synaptic innervation and finally glutamatergic synaptic innervation (Figs. 1 \& 3). GABA exerts a depolarising action during the initial development of new DGCs due to their high $\left[\mathrm{Cl}^{-}\right]_{\mathrm{i}}$ from the expression of NKCC1 (Fig. 2). Using a retrovirus mediated "single-cell genetic" approach, we showed that converting GABA-induced depolarisation into hyperpolarisation led to significant defects in GABAergic and glutamatergic synaptogenesis as well as in the dendritic development of newly generated neurons in the adult brain (Figs. $3 \& 4$ ). In the adult brain, ambient GABA is known to regulate the excitability of certain mature neurons, notably in the cerebellum and dentate gyrus ${ }^{13-15,24,25}$. Here we showed that tonic GABA activation depolarises newborn DGCs (Fig. 2; Supplementary Fig. 3c), and more importantly, it constitutes the majority of GABA-induced activation during the initial integration process when the phasic GABA activation either does not exist or is weaker than the tonic activation (Figs. 2d \& 3b,c). The mechanism by which tonic GABA activation regulates neuronal development and synaptic integration of new DGCs in the adult brain remains to be determined. Both voltage-dependent ${ }^{8}$ and -independent $\mathrm{Ca}^{2+}$-permeable channels ${ }^{26}$ could be involved. Newborn DGCs in the adult brain express high levels of low-voltage activated T-type $\mathrm{Ca}^{2+}$ channels that are activated below $-57 \mathrm{mV}^{8}$. Thus, tonic depolarisation by GABA may lead to an activation of these $\mathrm{Ca}^{2+}$ channels and subsequent $\mathrm{Ca}^{2+}$ influx. Tonic activation may also provide an initial depolarization that allows a small phasic GABA activation to reach the threshold of these $\mathrm{Ca}^{2+}$ channels.

Activity-dependent anatomical reorganization is widely regarded as a fundamental mechanism of developmental and adult neural plasticity 27,28 . Within the dentate gyrus, principle neurons and interneurons form extensive recurrent connections. The levels of ambient GABA, regulated by interneuron activities (Supplementary Fig. 2c), may serve as a general indicator of the dynamic neuronal network activity. Our study thus suggests an unexpected mechanism for activity-dependent regulation of adult neurogenesis where newborn neurons, before receiving any synaptic innervations, may sense neuronal network activities through local ambient GABA levels. Many physiological and pathological stimulations, such as neurosteroids or epilepsy, 
affect GABA signalling 15,25 , therefore they may potentially regulate the integration of new neurons in the adult brain. Our study may also have significant implications in neuronal cell replacement therapy for degenerative neurological diseases using various stem cells.

\section{Methods}

For detailed methods see Supplementary Information.

\section{Construction, production and stereotaxic injection of engineered retroviruses}

Engineered self-inactivating murine retroviruses were used to label and genetically manipulate proliferating cells and their progeny 6,7 . GFP and shRNA were co-expressed under the control of the EF1 $\alpha$ and human $\mathrm{U} 6$ promoter $^{22}$, respectively. The following short hairpin sequences were used: ACACACTTGTCCTGGGATT (shRNA-NKCC1-1); GGACAATATCTACCCAGCT (shRNA-NKCC1-2); AGTTCCAGTACGGCTCCAA (shRNA-DsRed). The specificity and efficiency of the shRNAs were validated and high titers of engineered retroviruses $\left(1 \times 10^{9} \mathrm{unit} / \mathrm{ml}\right)$ were produced as previously described 6 .

Adult (7-8 weeks old) female C57Bl/6 mice (Charles River) and NKCC1-/- mice ${ }^{23}$ housed under standard condition were anaesthetized and retroviruses were stereotaxically injected at 4 sites $(0.5 \mu \mathrm{l}$ per site at $0.25 \mu \mathrm{l} / \mathrm{min}$ ) with the following coordinates (from bregma in $\mathrm{mm}$ ) as previously described 6 : anterioposterior $=-2$, lateral $= \pm 1.6$, ventral $=2.5$; anterioposterior $=$ -3 , lateral $= \pm 2.6$, ventral $=3.2$. A total of 530 animals were used and all animal procedures were in accordance with institutional guidelines.

\section{Immunostaining, confocal imaging and analysis}

Coronal brain sections ( $40 \mu \mathrm{m}$ thick) were prepared and processed for immunostaining using the following antibodies as previously described ${ }^{6}$ : goat anti-DCX (Santa Cruz, 1:500), mouse anti-NeuN (Chemicon, 1:200), mouse anti-NKCC1 (T4, Developmental Studies Hybridoma Bank, 1:200), rabbit anti-KCC2 (Upstate, 1:200) and rabbit Ki67 (1:500; Novocastra). The sections were also stained for 4',6-diaminodino-2-phenylindole (DAPI, 1:5000). Images were acquired on a Zeiss LSM 510 META multiphoton confocal system (Carl Zeiss) using a multitrack configuration. For dendritic analysis, three-dimensional reconstructions of the dendritic processes of each $\mathrm{GFP}^{+}$neuron were made from Z-series stacks of confocal images. The projection images were semi-automatically traced with NIH ImageJ using NeuronJ plugin. The total dendritic length and branch number of each individual $\mathrm{GFP}^{+}$neuron in the granule cell layer were analyzed. Statistical significance $(P<0.01)$ was assessed using the KolmogorovSmirnov test. The Sholl analysis for dendritic complexity was carried out by counting the number of dendrites that cross a series of concentric circles at $5 \mu \mathrm{m}$ intervals from the soma. Statistical significance $(P<0.05)$ was assessed using the student t-test.

\section{Electrophysiology}

Mice housed under standard conditions were processed for slice preparation and electrophysiology as previously described ${ }^{6}$. Electrophysiological recordings were obtained at $32^{\circ} \mathrm{C}-34^{\circ} \mathrm{C}$. GFP ${ }^{+}$DGCs were identified by their green fluorescence, location within the subgranule or granule cell layer, neuronal morphology and capacity to generate $\mathrm{Na}^{+}$spikes (7 dpi and onwards). We monitored $\mathrm{V}_{\text {rest }}$ based on the reversal potential of the $\mathrm{K}^{+}$current through cell-attached patches (Supplementary Fig. 3b) to avoid an underestimation of $V_{\text {rest }}$ due to a shunt through the seal contact between the pipette and the membrane in perforated and wholecell recording $18,29,30$. Microelectrodes (4-6 M) were filled with the following (in mM): 120.0 potassium gluconate, $15 \mathrm{KCl}, 4 \mathrm{MgCl}_{2}$, 0.1 EGTA, 10.0 HEPES, $4 \mathrm{MgATP}, 0.3 \mathrm{Na}_{3} \mathrm{GTP}, 7$ phosphocreatine ( $\mathrm{pH} 7.4,300 \mathrm{mOsm})$. For characterizing tonic GABA currents, potassium salt was substituted by $\mathrm{CsCl}$ in the intracellular solution and TTX $(0.5 \mu \mathrm{M})$ was added to the 
recording solution ${ }^{14}$. Additional drugs were used with the following final concentrations: bicuculline (100 $\mu \mathrm{M}$, Sigma), SR95531 (100 $\mu$ M, Tocris), NO-711 (2.5 $\mu$ M, Sigma). Data were collected using an Axon 200B amplifier and acquired via a DigiData 1322A (Axon Instruments) at $10 \mathrm{kHz}$. The series and input resistances were monitored and only those with changes less than $20 \%$ during experiments were analyzed. The series resistance ranged between $10-30 \mathrm{M}$ and was uncompensated. For perforated patch recordings, the gramicidin stock (10 $\mathrm{mg} / \mathrm{ml}$ in DMSO) was diluted in the pipette solution (in $\mathrm{mM}: 135 \mathrm{CsCl}, 4 \mathrm{MgCl}_{2}, 0.1$ EGTA, 10 HEPES, pH 7.4, $300 \mathrm{mOsm}$ ) to a final concentration of $25 \mu \mathrm{g} / \mathrm{ml}$ just before experiments. Perforated patch recordings with a series resistance of $<80 \mathrm{M}$ and without significant changes $(>25 \%)$ during recordings were used for data analysis. For measurement of $\mathrm{E}_{\mathrm{GABA}}$, focal pressure ejection of $10 \mu \mathrm{M}$ GABA via a puffer pipette controlled by a Picrospitzer $(5 \mathrm{~ms}$ puff at $3-5 \mathrm{psi}$ ) was used to activate $\mathrm{GABA}_{\mathrm{A}}$ Rs on the $\mathrm{GFP}^{+}$DGCs with gramicidin perforated patch under voltage-clamp at different holding potentials (Supplementary Fig. 3a). The peak amplitude and holding potential were plotted and the $\mathrm{E}_{\mathrm{GABA}}$ was determined for each cell. Intracellular chloride concentrations were calculated with the following equation: $\left[\mathrm{Cl}^{-}\right]_{\mathrm{i}}=$ $\left[\mathrm{Cl}^{-}\right]_{\mathrm{o}} \mathrm{e}\left(\mathrm{E}_{\mathrm{GABA}} \mathrm{F} / \mathrm{RT}\right)\left(\left[\mathrm{Cl}^{-}\right]_{\mathrm{o}}=134.1 \mathrm{mM}\right.$; Supplementary Fig. 4).

A bipolar electrode (World Precision Instruments) was used to stimulate (100 $\mu$ s duration) the perforant pathway input to the dentate gyrus. The stimulus intensity $(\sim 30 \mu \mathrm{A})$ were maintained for all experiments. To examine the evoked synaptic transmission, a train of 20 stimuli were delivered at $0.1 \mathrm{~Hz}$. To confirm a lack of evoked synaptic transmission, the stimulation intensity was then increased to $200 \mu \mathrm{A}$.

\section{Supplementary Material}

Refer to Web version on PubMed Central for supplementary material.

\section{Acknowledgements}

We would like to thank C.F. Stevens, F.H. Gage, R. Huganir, K.-W. Yau and J. Bischofberger for comments and suggestions, L-h. Liu for technical support, E. Delpire for NKCC1 knockout mice and mouse NKCC1 cDNA, N. Gaiano, D. Sun and D. Pradhan for reagents and help. This work was supported by the National Institute of Health (H.S.), Klingenstein Fellowship Awards in the Neurosciences (G-1. M. and H.S.), the Whitehall Foundation (G-1. M.) and The Robert Packard Center for ALS Research at Johns Hopkins (H.S.).

\section{References}

1. Kempermann G, Gage FH. New nerve cells for the adult brain. Sci Am 1999;280:48-53. [PubMed: 10231988]

2. Fuchs E, Gould E. Mini-review: in vivo neurogenesis in the adult brain: regulation and functional implications. Eur J Neurosci 2000;12:2211-4. [PubMed: 10947799]

3. Temple S, Alvarez-Buylla A. Stem cells in the adult mammalian central nervous system. Curr Opin Neurobiol 1999;9:135-41. [PubMed: 10072370]

4. Doetsch F, Hen R. Young and excitable: the function of new neurons in the adult mammalian brain. Curr Opin Neurobiol 2005;15:121-8. [PubMed: 15721754]

5. Ming, Gl; Song, H. Adult neurogenesis in the mammalian central nervous system. Annu Rev Neurosci 2005;28:223-50. [PubMed: 16022595]

6. van Praag H, et al. Functional neurogenesis in the adult hippocampus. Nature 2002;415:1030-4. [PubMed: 11875571]

7. Carleton A, Petreanu LT, Lansford R, Alvarez-Buylla A, Lledo PM. Becoming a new neuron in the adult olfactory bulb. Nat Neurosci 2003;6:507-18. [PubMed: 12704391]

8. Schmidt-Hieber C, Jonas P, Bischofberger J. Enhanced synaptic plasticity in newly generated granule cells of the adult hippocampus. Nature 2004;429:184-7. [PubMed: 15107864]

9. Ben-Ari Y. Excitatory actions of gaba during development: the nature of the nurture. Nat Rev Neurosci 2002;3:728-39. [PubMed: 12209121] 
10. Owens DF, Kriegstein AR. Is there more to GABA than synaptic inhibition? Nat Rev Neurosci 2002;3:715-27. [PubMed: 12209120]

11. Delpire E. Cation-Chloride Cotransporters in Neuronal Communication. News Physiol Sci 2000;15:309-312. [PubMed: 11390932]

12. Payne JA, Rivera C, Voipio J, Kaila K. Cation-chloride co-transporters in neuronal communication, development and trauma. Trends Neurosci 2003;26:199-206. [PubMed: 12689771]

13. Overstreet LS, Westbrook GL. Paradoxical reduction of synaptic inhibition by vigabatrin. J Neurophysiol 2001;86:596-603. [PubMed: 11495935]

14. Nusser Z, Mody I. Selective modulation of tonic and phasic inhibitions in dentate gyrus granule cells. J Neurophysiol 2002;87:2624-8. [PubMed: 11976398]

15. Farrant M, Nusser Z. Variations on an inhibitory theme: phasic and tonic activation of GABA(A) receptors. Nat Rev Neurosci 2005;6:215-29. [PubMed: 15738957]

16. Wang LP, Kempermann G, Kettenmann H. A subpopulation of precursor cells in the mouse dentate gyrus receives synaptic GABAergic input. Mol Cell Neurosci 2005;29:181-9. [PubMed: 15911343]

17. Overstreet Wadiche, L. S., Bromberg, D. A., Bensen, A. L. \& Westbrook, G. L. GABAergic Signaling to Newborn Neurons in Dentate Gyrus. J Neurophysiol[Epub ahead of print] (2005).

18. Wang DD, Krueger DD, Bordey A. GABA depolarizes neuronal progenitors of the postnatal subventricular zone via GABAA receptor activation. J Physiol 2003;550:785-800. [PubMed: 12807990]

19. Liu X, Wang Q, Haydar TF, Bordey A. Nonsynaptic GABA signaling in postnatal subventricular zone controls proliferation of GFAP-expressing progenitors. Nat Neurosci 2005;8:1179-87. [PubMed: 16116450]

20. Tozuka Y, Fukuda S, Namba T, Seki T, Hisatsune T. GABAergic excitation promotes neuronal differentiation in adult hippocampal progenitor cells. Neuron 2005;47:803-15. [PubMed: 16157276]

21. Owens DF, Boyce LH, Davis MB, Kriegstein AR. Excitatory GABA responses in embryonic and neonatal cortical slices demonstrated by gramicidin perforated-patch recordings and calcium imaging. J Neurosci 1996;16:6414-23. [PubMed: 8815920]

22. Paddison PJ, Caudy AA, Bernstein E, Hannon GJ, Conklin DS. Short hairpin RNAs (shRNAs) induce sequence-specific silencing in mammalian cells. Genes Dev 2002;16:948-58. [PubMed: 11959843]

23. Delpire E, Lu J, England R, Dull C, Thorne T. Deafness and imbalance associated with inactivation of the secretory Na-K-2Cl co-transporter. Nat Genet 1999;22:192-5. [PubMed: 10369265]

24. Chadderton P, Margrie TW, Hausser M. Integration of quanta in cerebellar granule cells during sensory processing. Nature 2004;428:856-60. [PubMed: 15103377]

25. Semyanov A, Walker MC, Kullmann DM, Silver RA. Tonically active GABA A receptors: modulating gain and maintaining the tone. Trends Neurosci 2004;27:262-9. [PubMed: 15111008]

26. Chavas J, Forero ME, Collin T, Llano I, Marty A. Osmotic tension as a possible link between GABA (A) receptor activation and intracellular calcium elevation. Neuron 2004;44:701-13. [PubMed: 15541317]

27. Cline HT. Dendritic arbor development and synaptogenesis. Curr Opin Neurobiol 2001;11:118-26. [PubMed: 11179881]

28. Wong RO, Ghosh A. Activity-dependent regulation of dendritic growth and patterning. Nat Rev Neurosci 2002;3:803-12. [PubMed: 12360324]

29. Tyzio R, et al. Membrane potential of CA3 hippocampal pyramidal cells during postnatal development. J Neurophysiol 2003;90:2964-72. [PubMed: 12867526]

30. Verheugen JA, Fricker D, Miles R. Noninvasive measurements of the membrane potential and GABAergic action in hippocampal interneurons. J Neurosci 1999;19:2546-55. [PubMed: 10087068] 

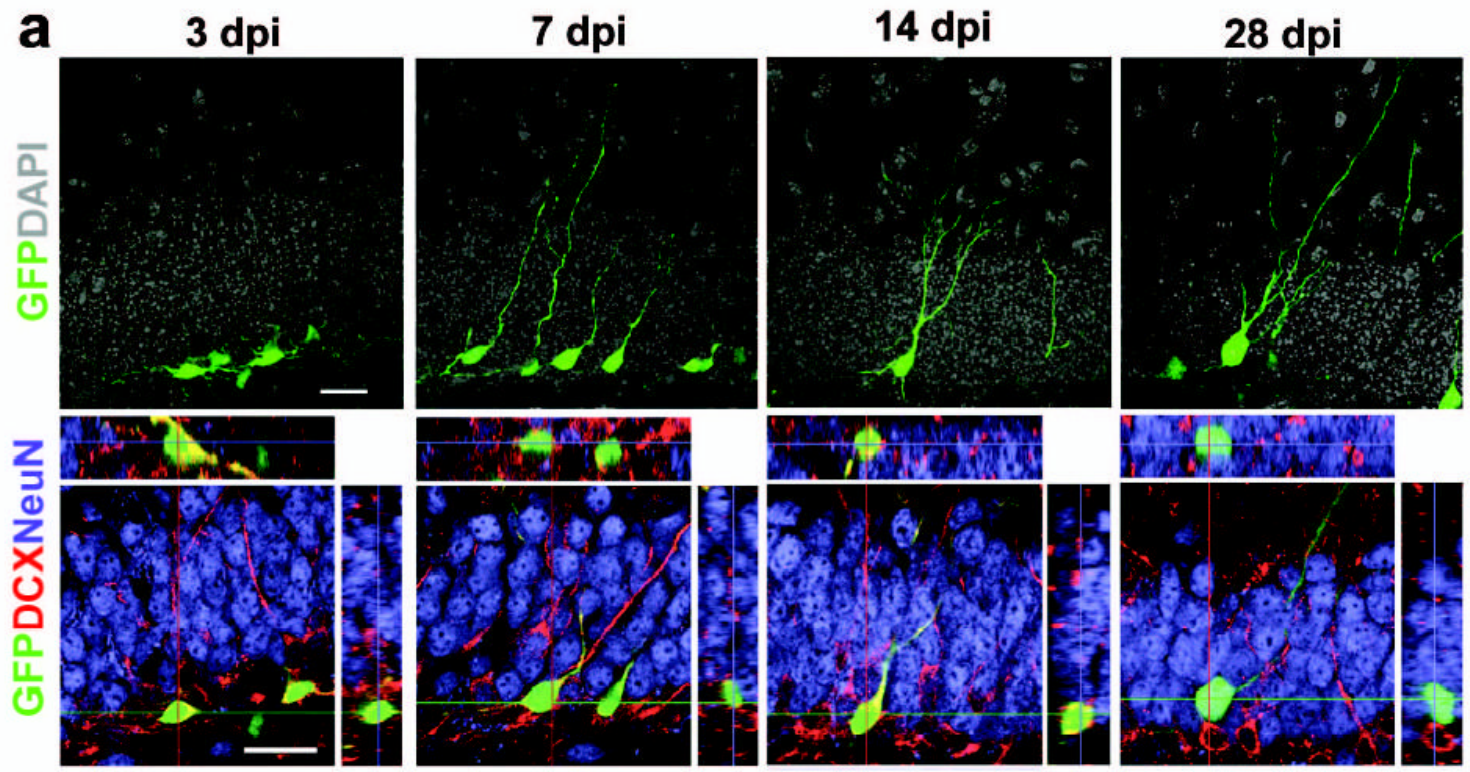

b Tonic GABA currents

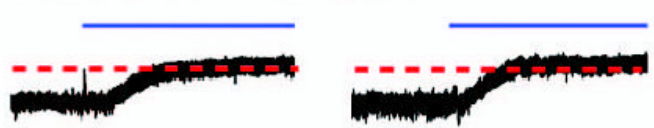

\section{Evoked GABAergic PSCs}
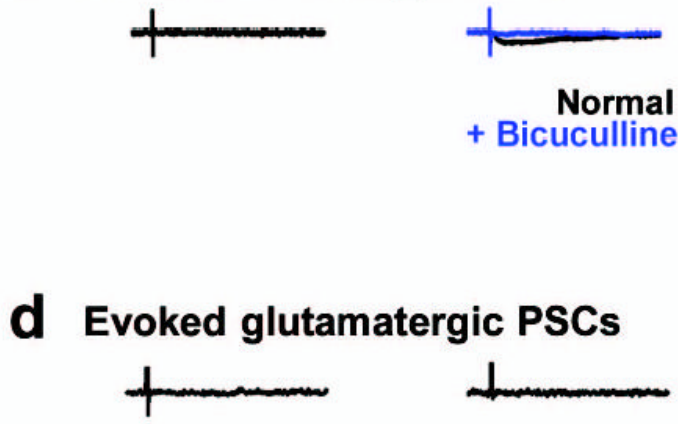

+ Bicuculline
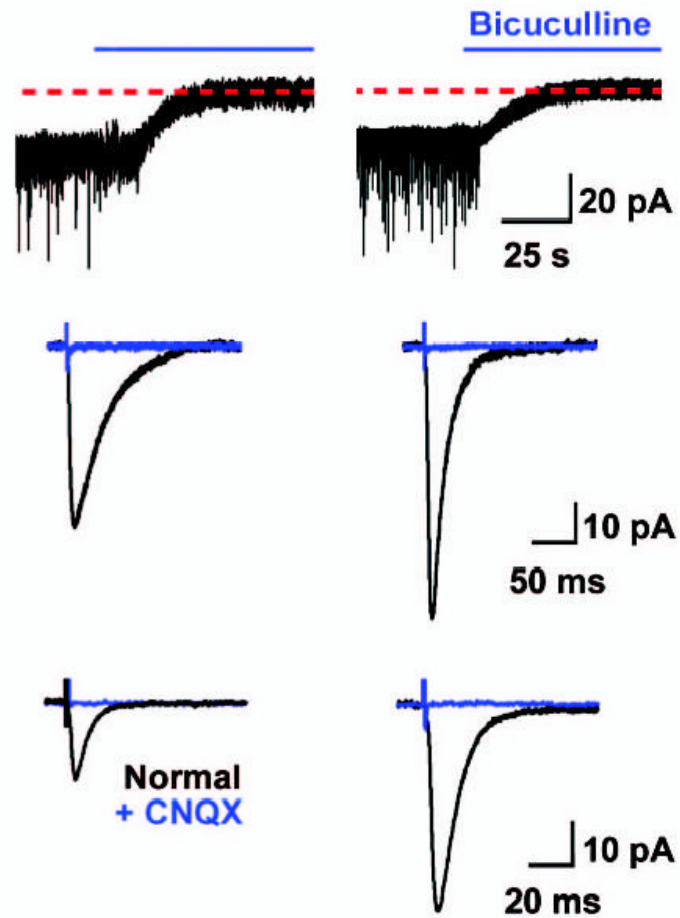

Figure 1.

Development of newborn DGCs in the adult mice. a, Confocal images of new DGCs $\left(\mathrm{GFP}^{+}\right.$, green) at different stages. Shown are projections (top) and confocal images of immunostaining (bottom) for doublecortin (DCX, red) and NeuN (blue) with orthogonal views to confirm the co-localization of GFP and DCX or NeuN. Scale bars: $20 \mu \mathrm{m}$. b-d, Synaptic integration of newborn DGCs. Shown are sample recording traces from $\mathrm{GFP}^{+} \mathrm{DGCs}$ under whole-cell voltage-clamp $\left(\mathrm{V}_{\mathrm{m}}=-65 \mathrm{mV}\right)$. Tonic currents shown are continuous recordings before and after adding bicuculline $(100 \mu \mathrm{M}$, blue). Evoked PSCs shown are averaged responses from 5 consecutive stimuli before (black) and after (blue) adding bicuculline (10 $\mu \mathrm{M})$ or CNQX (50 $\mu \mathrm{M})$, as indicated. Scale bars: $20 \mathrm{pA}$ and $25 \mathrm{~s}$ (b); $10 \mathrm{pA}$ and $50 \mathrm{~ms}$ (c); $10 \mathrm{pA}$ and $20 \mathrm{~ms}(\mathbf{d})$. 
a

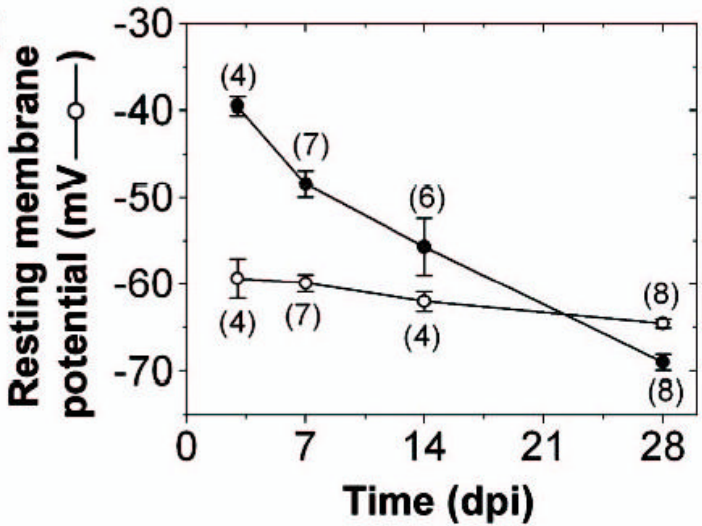

b

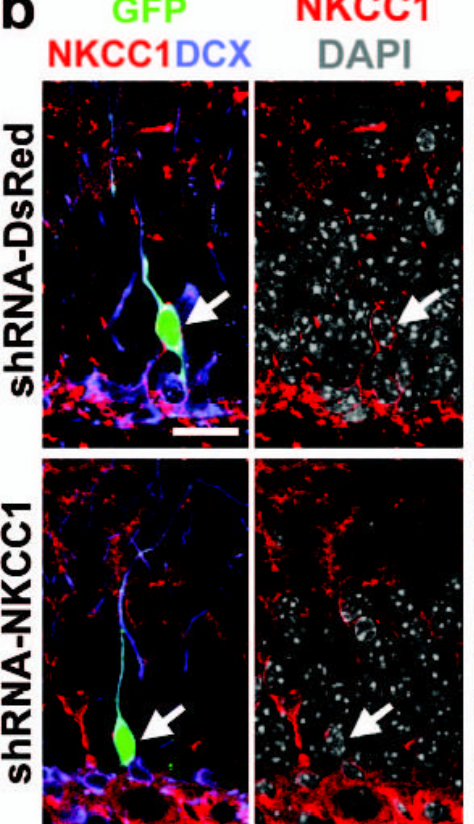

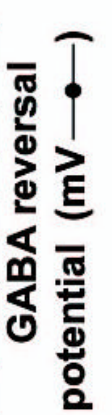

KCC2

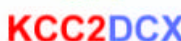

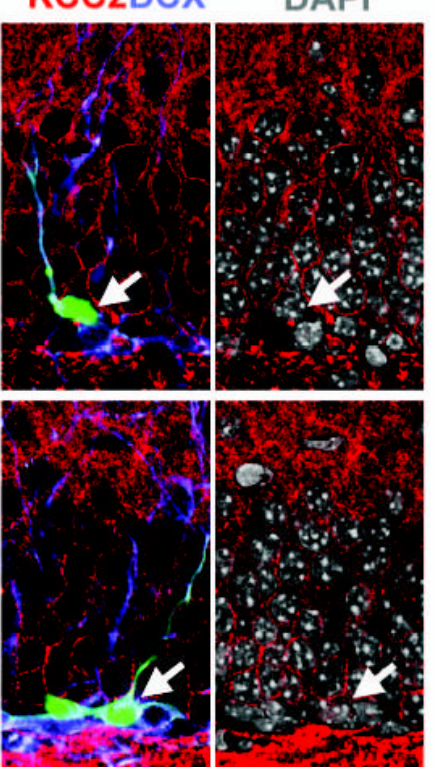
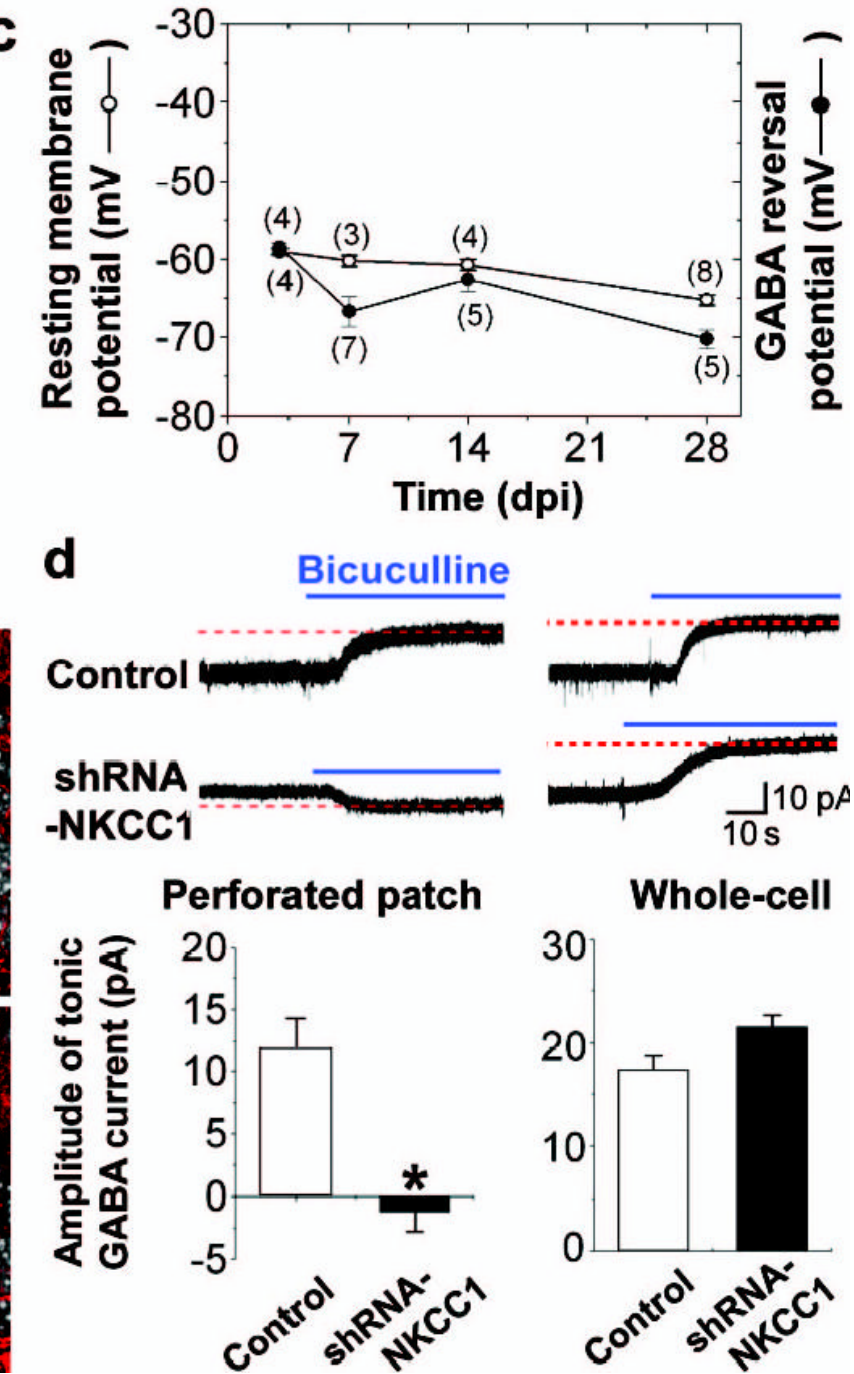

Figure 2.

Nature of GABA-induced activation in newborn DGCs in the adult brain. a, Resting membrane potentials $\left(\mathrm{V}_{\text {rest }}\right)$ and GABA-reversal potentials $\left(\mathrm{E}_{\mathrm{GABA}}\right)$ of $\mathrm{GFP}^{+}$DGCs. Values represent mean \pm s.e.m. Numbers associated with symbols refer to the number of cells examined. $\mathbf{b}$, Retrovirus mediated co-expression of GFP and shRNAs specific for NKCC1, but not a control shRNA (shRNA-DsRed), reduced NKCC1 expression and had no effects on KCC2 expression in newborn DGCs (7 dpi). Shown are confocal images of GFP (green) and immunostaining of NKCC1 or KCC2 (red), DCX (blue) and DAPI (gray), respectively. Arrows point to GFP ${ }^{+}$ DGCs. Scale bar: $20 \mu \mathrm{m}$. c, $\mathrm{V}_{\text {rest }}$ and $\mathrm{E}_{\mathrm{GABA}}$ in shRNA-NKCC1+ newborn DGCs. Similar as in (a). d, Tonic GABA currents in newborn DGCs (7dpi) recorded under gramicidin perforated patch or break-in whole-cell recording $\left(\mathrm{V}_{\mathrm{m}}=-65 \mathrm{mV}\right)$. Blue lines indicate the addition of bicuculline $(100 \mu \mathrm{M})$. Scale bars: $10 \mathrm{pA}$ and $10 \mathrm{~s}$. Values in the bar graph represent mean \pm s.e.m. $(n=6, * p<0.01$, ANOVA). 

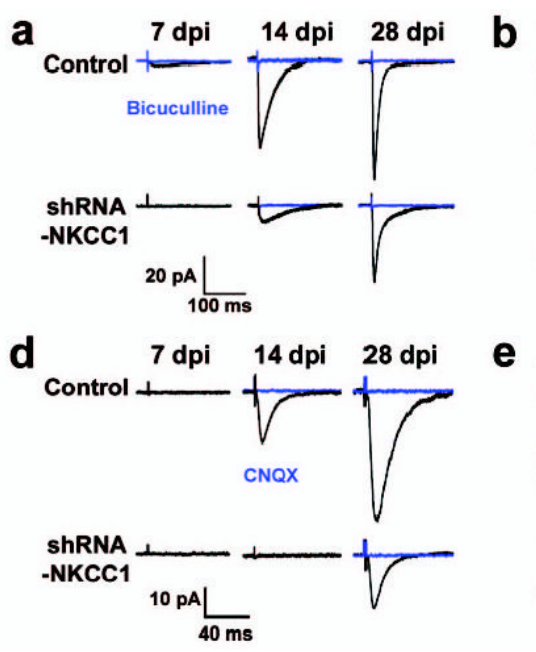
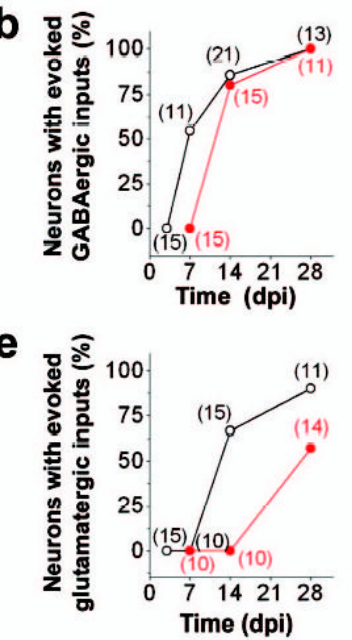
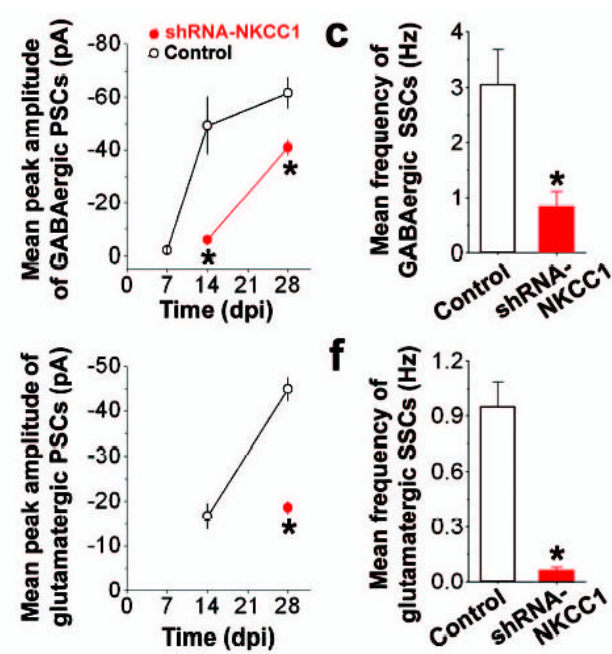

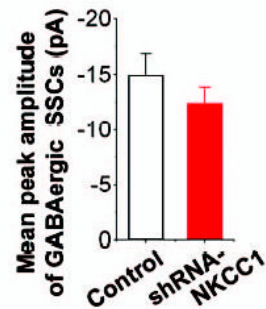

Figure 3.

Synaptic integration of newborn DGCs in the adult brain. a-c, Formation of GABAergic synaptic inputs by GFP DGCs. Shown in (a) are sample traces of evoked PSCs recorded under whole-cell voltage-clamp $\left(\mathrm{V}_{\mathrm{m}}=-65 \mathrm{mV}, 5 \mathrm{mM} \mathrm{Kyn}\right)$ before and after the addition of bicuculline $(10 \mu \mathrm{M})$. Scale bars: $20 \mathrm{pA}$ and $100 \mathrm{~ms}$. Also shown are the percentages of $\mathrm{GFP}^{+}$DGCs with detectable GABAergic PSCs, mean amplitude of GABAergic PSCs (b), mean frequency and peak amplitude of GABAergic SSCs recorded at $28 \mathrm{dpi}(\mathbf{c})$. Numbers associated with symbols refer to the number of cells examined. Values represent mean \pm s.e.m. ${ }^{*} p<0.01$, ANOVA). d-f, Formation of glutamatergic synaptic inputs by GFP ${ }^{+}$DGCs. Same as in $(\mathbf{a}-\mathbf{c})$, except that the recordings were carried out in the presence of bicuculline $(10 \mu \mathrm{M})$. Blue lines indicate the addition of CNQX $(50 \mu \mathrm{M})$. Scale bars: $10 \mathrm{pA}$ and $40 \mathrm{~ms}$. 


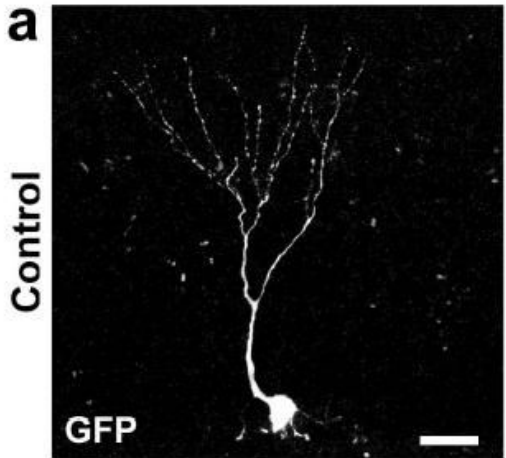

2D projection of 3D reconstructions
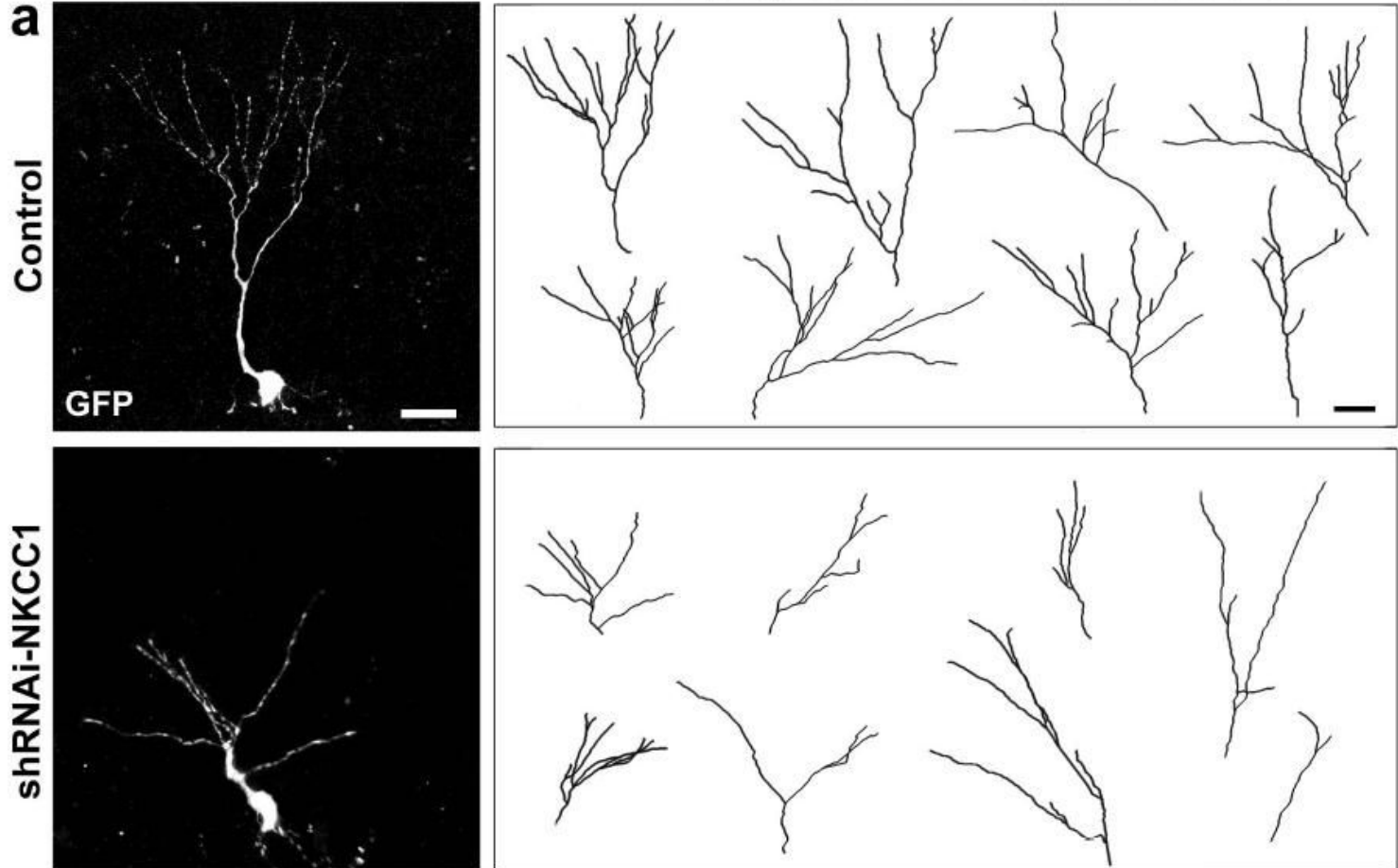

b

○ Control

- shRNA-NKCC1
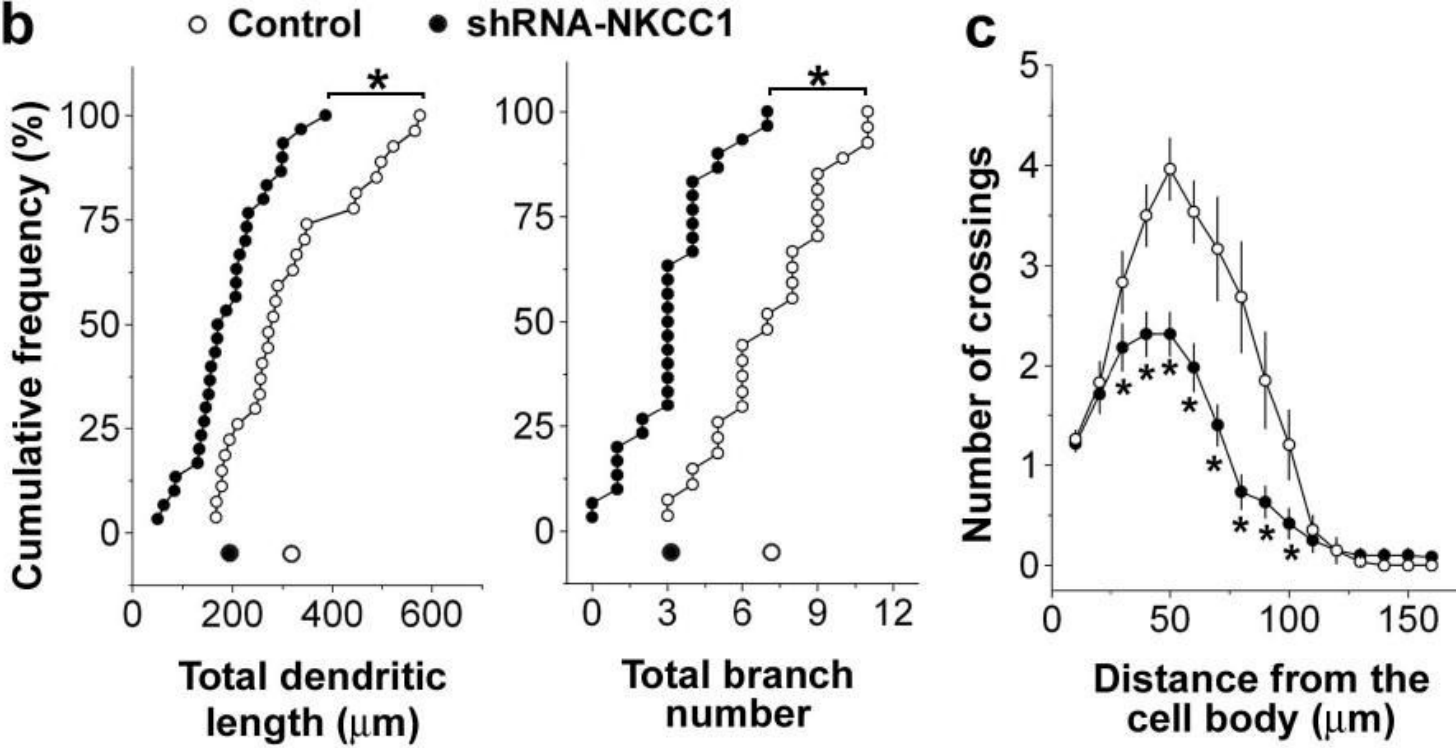

Figure 4.

Dendritic development of newborn DGCs in the adult brain. a, Confocal three-dimensional reconstruction of dendrites of control or shRNA-NKCC1 ${ }^{+}$DGCs (14 dpi). Scale bar: $20 \mu \mathrm{m}$. b, Quantification of the total dendritic length and branch number of newborn DGCs. Each symbol represents data from a single control (empty) or shRNA-NKCC1 ${ }^{+}$(solid) DGC at 14 dpi. Dots along the $\mathrm{X}$-axis represent mean values. (*: $p<0.01$, Kolmogorov-Smirnov test). c, Sholl analysis of dendritic complexity of $\mathrm{GFP}^{+}$DGCs (14 dpi). Values represent mean \pm s.e.m. $(n=27 ; *: p<0.05$, Student's t-test). 